\title{
Optimization of ultrasonic-microwave synergistic extraction of flavonoids from sweet potato leaves by response surface methodology
}

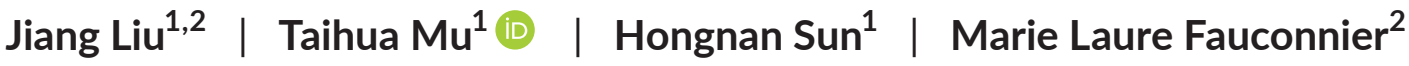

\author{
${ }^{1}$ Key Laboratory of Agro-Products \\ Processing, Ministry of Agriculture; Institute \\ of Food Science and Technology, Chinese \\ Academy of Agricultural Sciences, Beijing, \\ P.R. China \\ ${ }^{2}$ Laboratory of General and Organic \\ Chemistry, University of Liege, Gembloux \\ Agro-Bio Tech, Gembloux, Belgium

\section{Correspondence} \\ Taihua Mu, Key Laboratory of \\ Agro-Products Processing, Ministry of \\ Agriculture; Institute of Food Science \\ and Technology, Chinese Academy of \\ Agricultural Sciences, 2 Yuanmingyuan \\ West Road, Haidian District, PO Box 5109, \\ Beijing 100193, P.R. China. \\ Email:mutaihua@126.com \\ Funding information \\ Natural Science Funding of China, Grant/ \\ Award Number: 31701614; National Key \\ R\&D Program of China, Grant/Award \\ Number: 2016YFE0133600; China \\ Agriculture Research System, Grant/Award \\ Number: CARS-10-B21; Collaborative \\ Innovation Task of CAAS, Grant/Award \\ Number: CAAS-XTCX2016005
}

\begin{abstract}
Ultrasonic-microwave synergistic extraction was used to extract flavonoids from sweet potato leaves (SPL) by response surface methodology. The optimal conditions for flavonoids extraction were $1: 40(\mathrm{~g} / \mathrm{ml})$ of solid-liquid ratio, $57^{\circ} \mathrm{C}$ of extraction temperature, $76 \mathrm{~s}$ of extraction time, and $72 \%(\mathrm{v} / \mathrm{v})$ ethanol for 2 times, the highest extraction efficiency was $91.65 \pm 3.37 \%$. After purification, the flavonoids purity reached to $76.10 \pm 3.11$ (\%, DW). The result of high-performance liquid chromatography revealed 11 compounds including astragalin $(473.8 \pm 7.3 \mathrm{mg} / \mathrm{g}$, DW), quercetrin $(86.5 \pm 0.7 \mathrm{mg} / \mathrm{g}$, DW), 4,5-chlorogenic acid $(76.4 \pm 0.5 \mathrm{mg} / \mathrm{g}$, DW), isoquercitrin (62.4 $\pm 0.4 \mathrm{mg} / \mathrm{g}$, DW), tiliroside $(18.8 \pm 0.3 \mathrm{mg} / \mathrm{g}$, DW), quercetin $(12.5 \pm 0.2 \mathrm{mg} / \mathrm{g}$, DW), 3,4,5-chlorogenic acid (6.5 $\pm 0.2 \mathrm{mg} / \mathrm{g}$, DW), caffeic acid $(6.1 \pm 0.2 \mathrm{mg} / \mathrm{g}$, DW), kaempferol $(6.0 \pm 0.2 \mathrm{mg} / \mathrm{g}$, DW), myricetrin $(5.9 \pm 0.1 \mathrm{mg} / \mathrm{g}$, DW), and rhamnetin $(4.3 \pm 0.1 \mathrm{mg} / \mathrm{g}$, DW) in sweet potato leaf flavonoids, which possessed good antioxidant activity compared to soy isoflavones, ginkgo biloba extract, and propolis flavone. The $\mathrm{IC}_{50}$ value of sweet potato leaf flavonoids was $13.26 \pm 0.09 \mu \mathrm{g} / \mathrm{ml}$ in ferric reducing antioxidant power and $5.41 \pm 0.21$ in 2, 2'-azino-bis(3-ethylbenzothiazoline-6-sulphonic acid) scavenging capacity, respectively.

\section{Practical applications}

China is the leading country of sweet potato production in the world, but sweet potato leaves (SPL) have been neglected except for a partial use as livestock feed in most parts of China, and detailed reports on the effective components in the leaves are scarce. Ultrasonic-microwave synergistic extraction is an efficient way to select flavonoids from SPL which has a potential to be extended in natural flavonoids industry.
\end{abstract}

\section{1 | INTRODUCTION}

Flavonoids are a large class of secondary metabolites widely existing in plants. Its basic structure is flavane nuclear parent (2-benzyl ketone), which means two benzene rings ( $A$ ring and $B$ ring) are connected by pyran ring ( $C$ ring), often containing hydroxyl, methoxy, methyl, isoamyl group, and other substituents, widely exists in the fruit, leaf, wood, and bark of plant. Flavonoids possess biological activities such as antioxidant activity, improving blood circulation, reducing cholesterol, preventing ultraviolet, inhibiting angiogenesis, antibacterial, and antiinflammatory (Chen et al., 2011). 
that SPL flavonoids possess antioxidant activity (Huang et al., 2013), anti-LDL oxidation activity (Taira, Taira, Ohmine, \& Nagata, 2013), anticytotoxic activity (Liao et al., 2011), and antiproliferation activity (Taira et al., 2013).

It is well known that flavonoids are soluble in polar solvents and are usually extracted by aqueous mixtures of organic solvent such as methanol, ethanol and acetone, and 70\% ethanol extract had the highest yield of total flavonoid (3.4 mg QE/g DW) (Fu et al., 2016), meanwhile methanol and acetone are toxic and ethanol and its aqueous mixture are the safest solutions for extraction. The extraction of flavonoids from SPL included conventional stirring extraction (Miu et al., 2011), reflux extraction (Liao et al., 2011), sonication extraction (Isabelle et al., 2010), and dynamic high pressure microfluidizationassisted extraction (Huang et al., 2013), which were time-consuming, activity destroying, solvent wasting, and not eco-friendly.

Ultrasonic-microwave synergistic extraction (UMSE) is the extraction method combined with ultrasonic and microwave which is economic and time-saving comparing with other new extraction technologies such as pressurized liquid extraction, supercritical fluid extraction, enzyme-assisted extraction, and pulsed electric field extraction (Mandal, Mohan, \& Hemalatha, 2007). Ultrasound-assisted extraction (UAE) uses ultrasound to produce "cavitation" in liquid, destroying plant cell and cell membrane structure, thus enhancing the penetration of cell contents through cell membrane, which is beneficial to the release and dissolution of flavonoids (Chemat, Zill-e-Huma, \& Khan, 2011). The biggest advantage of UAE is to increase the yield significantly such as the yield of chlorogenic acid from artichoke leaves extracted by $80 \%$ methanol for $15 \mathrm{~min}$ increased $50 \%$ toward to maceration at ambient temperature, which was close to the yield by boiling extraction (Saleh et al., 2016). Microwave-assisted extraction (MAE) is based on the principle of its penetrating heating, in the microwave field, the absorption difference of various materials makes certain components of the matrix material or some components in the extraction system be selectively heated and get enough energy to escape (Mustapa, Martin, Gallego, Mato, \& Cocero, 2015). The biggest advantage of MAE is time-saving, compared to $2 \mathrm{hr}$ of conventional reflux extraction of total polyphenols from the leaves of Pistacia lentiscus, the MAE could only take $60 \mathrm{~s}$ to attain the highest yield of total polyphenols, saving more than $99 \%$ of the time (Dahmoune et al., 2014). Meanwhile, the highest antioxidant activity could be obtained in $70 \%$ ethanol extracts from elecampane (Inula helenium) roots collected by UAE which was $86.0 \mathrm{mM}$ TE/g DW in ABTS and $67.0 \mathrm{mM} \mathrm{TE} / \mathrm{g}$ DW in ferric reducing antioxidant power (FRAP) (Petkova, Ivanov, Vrancheva, Denev, \& Pavlov, 2016).

Response surface methodology (RSM) is an experimental design which utilize minimum trials to optimize the multiple variables experiments, at the same time detecting the interrelationship between the variables comparing to the traditional orthogonal design (Ferreira et al., 2007). Especially, for the bioactive compounds extraction optimization experiments, RSM shows its superiority which could flexibly optimize the dependent variables more than one according to the same variables (Derrien, Badr, Gosselin, Desjardins, \& Angers, 2017).
In the present study, flavonoids were extracted from SPL by UMSE. The optimal extraction parameters were assessed with RSM. The individual flavone composition was analyzed by highperformance liquid chromatography (HPLC). In addition, the antioxidant activity was investigated and compared with some common commercial flavonoids (soy isoflavones, ginko biloba extract, and propolis flavone). The aim of this study was to exploit the potentialities of UMSE application in the industrial extraction of flavonoids and the application of SPL as a good source in commercial flavonoids production.

\section{2 | MATERIALS AND METHODS}

\subsection{Materials}

According to the previous study in our lab (Sun, Mu, Xi, Zhang, \& Chen, 2014), the SPL (leaf and petiole) from sweet potato cultivar Yuzi No. 7 was selected in the present study, which was heart type leaf, contained the highest polyphenols content and highest antioxidant activity among 40 cultivars around China. Fresh SPL were provided by Chongqing Sweet Potato Engineering and Technology Research Center, Chongqing, China. Tubers were sowed in the late period of June and SPL were harvested in the early period of September, 2017, approximate 70 days of growth period at Baiyun Village, Muer Town, Yubei District, Chongqing. Air transported to the lab immediately, washed gently, and dried by vacuum freezing and then grounded by ultra-micro pulverizer, sieved through 100mesh screens, and then sealed in aluminum foil bags and stored in the refrigerator at $4^{\circ} \mathrm{C}$ for further use.

Quercetin, kaempferol, myricetrin, astragalin, tiliroside, quercitrin, isoquercitrin, rhamnetin, caffeic acid (CA), 4, 5-chlorogenic acid (4, 5-CQA), and 3, 4, 5-chlorogenic acid (3, 4, 5-CQA) were purchased from An Apoptosis and Epigenetics Company (Houston, USA), the purity of the standards was more than $98 \%$. Soy isoflavones, ginkgo biloba extract, and propolis flavone were purchased from Shanghai Yuanye Biotech Co., Ltd. (Shanghai, China). 2, 4, 6-Tri (2-pyridyl)-1, 3, 5-triazine (TPTZ) and 2, 2'-azino-bis (3-ethylbenzothiazoline-6-sulphonic acid) (ABTS) was purchased from Solarbio Life Sciences (Beijing, China). Other analytical grade chemicals were obtained from Sinopharm Chemical Reagent (Beijing, China). HPLC grade solvents were purchased from Fisher Chemical (Beijing, China). HPLC water was prepared by the Molgene water purification system from Molecular (Shanghai, China).

\subsection{Basic components of SPL}

The SPL powder was analyzed for moisture, ash, crude protein, crude fat, crude fiber, carbohydrate, and flavonoids content. The moisture content was determined by AOAC method 930.15, ash content was determined by AOAC method 923.03, crude protein was analyzed according to Kjeldahl procedure by AOAC method 955.04, crude fat was determined by AOAC method 960.39, and crude fiber was determined by AOAC method 991.43. Carbohydrate content was 
calculated by subtracting the sum of ash, crude protein, crude fat, and crude fiber from 100. The flavonoids content in SPL powder was measured by colorimetric aluminum method described by Shi et al. (2016) with some improvements: $0.1 \mathrm{ml}$ of crude extract was absorbed and added into $10-\mathrm{ml}$ volumetric flask, $4.9 \mathrm{ml}$ of $30 \%$ ethanol was complemented, shook the solution for even, and $0.3 \mathrm{ml}$ of $5 \%$ $\mathrm{NaNO}_{2}$ was added later, mixing uniformity, and stood still for another $5 \mathrm{~min}$, then $0.3 \mathrm{ml}$ of $10 \% \mathrm{Al}\left(\mathrm{NO}_{3}\right)_{3}$ was added to the mixture, mixing evenly, and stood still for another $6 \mathrm{~min}$, finally $4.0 \mathrm{ml}$ of $4 \% \mathrm{NaOH}$ was added and constant volume to $10 \mathrm{ml}$ with $30 \%$ ethanol, lasting for $10 \mathrm{~min}$ and measured the absorbance by spectrophotometer at $320 \mathrm{~nm}$ (maximum absorbance), quercetin was taken as the standard.

\section{3 | Single factor for extraction efficiency of SPL flavonoids}

Five grams SPL powder was extracted by Ultrasonic-Microwave Assisted Extractor CW-2000 (ultrasonic frequency was $40 \mathrm{kHz}$, ultrasonic power was $50 \mathrm{~W}$, microwave frequency was $2450 \mathrm{MHz}$, microwave power was $100 \mathrm{~W}$, microwave wavelength was $0.12 \mathrm{~m}$ ) (Shanghai Xintuo Analytical Instruments Co., Ltd, China) for 1, 2, 3 times, immersed in ethanol solution of $10 \%, 30 \%, 50 \%, 70 \%, 90 \%$, $100 \%$ by solid-liquid ratio $(\mathrm{g} / \mathrm{ml})$ of $1: 10,1: 20,1: 30,1: 40,1: 50$ at the temperature of $35,45,55,65,75^{\circ} \mathrm{C}$ continued for $25,50,75,100$, $200,600,999 \mathrm{~s}$, centrifuged at $7,000 \mathrm{rpm}$ for $30 \mathrm{~min}$, the supernatant was combined and constant the volume to $500 \mathrm{ml}$ with $30 \%$ ethanol. The extraction efficiency (\%) was calculated by the equation:

$$
\begin{aligned}
\text { Extraction efficiency }(\%) & =\frac{\text { Content of SPL flavonoids extracted by certain parmeters }}{\text { Actual content of SPL flavonoids }} \\
& \times 100 \%
\end{aligned}
$$

\subsection{RSM optimization for extraction efficiency of SPL flavonoids}

Since 2 times and 3 times of extraction had no significant difference and 1:40 ( $\mathrm{g} / \mathrm{ml})$ of solid-liquid ratio had the highest extraction efficiency of SPL flavonoids according to result of single-factor experiments, meanwhile considering the solvent saving, extraction times, and solid-liquid ratio were settled down as 2 and 1:40. Three factors and three levels model consisted of 17 experiments with five replicates at central point were shown in Table 1 . Three experimental factors included extraction temperature $\left(X_{1}: 45,55\right.$, $\left.65^{\circ} \mathrm{C}\right)$, extraction time $\left(X_{2}: 50,75,100 \mathrm{~s}\right)$, and ethanol concentration $\left(X_{3}: 50 \%, 70 \%, 90 \%\right)$, which were optimized by Box-Behnken design, extraction efficiency of SPL flavonoids $(Y)$ was chosen as the dependent variable. The experimental data were fitted into the equation:

$$
Y=A o+\sum_{i=1}^{3} A i X i+\sum_{i=1}^{3} A i i X i 2+\sum_{i=1}^{2} \sum_{j=i+1}^{3} A i j X i X j
$$

where $Y$ was the response variable, $A_{0}$ was the intercept constant, $A_{i}$, $A_{i i}, A_{i j}$ were the regression coefficients for linear, quadratic, cross effect of $X_{1}, X_{2}, X_{3}, X_{i}, X_{j}$ were coded values of independent variables.

\begin{tabular}{|c|c|c|c|c|c|c|c|}
\hline \multirow{2}{*}{ Facto } & & & \multirow{2}{*}{\multicolumn{2}{|c|}{ Coded symbol }} & \multicolumn{3}{|l|}{ Level } \\
\hline & & & & & -1 & 0 & 1 \\
\hline \multicolumn{3}{|c|}{ Extraction temperature } & \multicolumn{2}{|l|}{$x_{1}$} & 45 & 55 & 65 \\
\hline \multicolumn{3}{|c|}{ Extraction time } & \multicolumn{2}{|l|}{$x_{2}$} & 50 & 75 & 100 \\
\hline \multicolumn{3}{|c|}{ Ethanol concentration } & $x_{3}$ & & 50 & 70 & 90 \\
\hline \multirow[t]{2}{*}{ Run } & \multicolumn{3}{|c|}{ Independent variables } & \multicolumn{2}{|c|}{ Measured } & \multicolumn{2}{|c|}{ Predicted } \\
\hline & $x_{1}$ & $x_{2}$ & $x_{3}$ & \multicolumn{2}{|c|}{$Y$} & \multicolumn{2}{|l|}{$Y$} \\
\hline 1 & -1 & -1 & 0 & \multicolumn{2}{|c|}{71.05} & \multicolumn{2}{|c|}{69.45} \\
\hline 2 & 1 & -1 & 0 & \multicolumn{2}{|c|}{82.95} & \multicolumn{2}{|c|}{82.06} \\
\hline 3 & -1 & 1 & 0 & \multicolumn{2}{|c|}{76.02} & \multicolumn{2}{|c|}{76.91} \\
\hline 4 & 1 & 1 & 0 & \multicolumn{2}{|c|}{74.07} & \multicolumn{2}{|c|}{75.49} \\
\hline 5 & -1 & 0 & -1 & \multicolumn{2}{|c|}{71.76} & \multicolumn{2}{|c|}{69.63} \\
\hline 6 & 1 & 0 & -1 & \multicolumn{2}{|c|}{84.19} & \multicolumn{2}{|c|}{82.95} \\
\hline 7 & -1 & 0 & 1 & \multicolumn{2}{|c|}{79.93} & \multicolumn{2}{|c|}{77.26} \\
\hline 8 & 1 & 0 & 1 & \multicolumn{2}{|c|}{85.97} & \multicolumn{2}{|c|}{87.74} \\
\hline 9 & 0 & -1 & -1 & \multicolumn{2}{|c|}{79.57} & \multicolumn{2}{|c|}{77.80} \\
\hline 10 & 0 & 1 & -1 & \multicolumn{2}{|c|}{73.71} & 76.38 & \\
\hline 11 & 0 & -1 & 1 & & & 84.7 & \\
\hline 12 & 0 & 1 & 1 & & & 66.2 & \\
\hline 13 & 0 & 0 & 0 & & & 89.17 & \\
\hline 14 & 0 & 0 & 0 & & & 89.17 & \\
\hline 15 & 0 & 0 & 0 & & & 89.17 & \\
\hline 16 & 0 & 0 & 0 & & & 89.17 & \\
\hline 17 & 0 & 0 & 0 & & & 89.17 & \\
\hline
\end{tabular}

TABLE 1 Experimental and predicted values of extraction efficiency in Box-Behnken design

Note. $X_{1}$ : extraction temperature $\left({ }^{\circ} \mathrm{C}\right) ; X_{2}$ : extraction time $(\mathrm{s}) ; X_{3}$ : ethanol concentration (\%); $Y$ : Extraction efficiency (\%) of SPL flavonoids.

The optimal extraction parameters were calculated by the "desirability" algorithm (Wong, Li, Li, Razmovski-Naumovski, \& Chan, 2017). To determine the optimization of extraction, the experimental variables in the Design Expert 8.0 were set as "in the range," meanwhile the response variable was set as "maximize." The combination of independent variables which made the highest desirability was chosen as the optimal extraction parameters.

\section{5 | SPL flavonoids purification}

Liquid-liquid extraction is the method to separate materials with different polarity using different organic solvent. Phenolic acids in SPL were mainly chlorogenic acid with different position substituted (Xi, Mu, \& Sun, 2015), which hardly dissolved in ethyl acetate while flavonoids could dissolved easily (Lu, Wang, Xie, \& Ding, 2013), so crude extract obtained by optimum process was vacuum concentrated to half volume and extracted by the same volume of petroleum ether in order to remove chlorophyll and other lipid soluble impurities, water phase was extracted by ethyl acetate with the same volume, the mixture was shaken thoroughly and stood for $5 \mathrm{~min}$ to make 
the ester phase and water phase separate completely, ethyl acetate phase was vacuum concentrated and evaporated to dryness, which was SPL flavonoids.

\subsection{Qualitative and quantitative analysis of SPL flavonoids}

The SPL flavonoids standards (quercetin, myricetrin, astragalin, tiliroside, quercitrin, isoquercitrin, kaempferol, rhamnetin, CA, 4,5CQA, 3,4,5-CQA) were qualified and quantified by HPLC (Shimadzu), which was equipped by the system control unit (CBM-20A), the UV detector (SPD-20A), the degaser (DGU-20A ${ }_{3}$ ), the liquid infusion unit (LC-20AB), the automatic sampler (SIL-20AC), and the column oven (CTO-20AC), $C_{18}$ was the column $(4.6 \times 150 \mathrm{~mm}, 5 \mu \mathrm{m}$, Inertsil ODS-SP, Shimadzu). The mobile phase was consisted of A and B, A: ultrapure water with $0.5 \%(\mathrm{v} / \mathrm{v})$ phosphoric acid, B: $100 \%$ acetonitrile, the elution procedure was performed as follows: $0-15.0 \mathrm{~min}$, 20\%-65\% B; $15.0-15.1 \mathrm{~min}, 65 \%-80 \%$ B; $15.1-20.0$ min, static $80 \%$ B; $20.0-20.1 \mathrm{~min}, 80 \%-20 \%$ B; $20.1-25.0 \mathrm{~min}$, static $20 \%$ B, the elution rate was $1.0 \mathrm{ml} / \mathrm{min}$ and the injection volume was $20 \mu \mathrm{l}$, the oven temperature was kept at $30^{\circ} \mathrm{C}$, and detection wavelength was set at $326 \mathrm{~nm}$ according to the method of Xi et al. (2015) with some modification.

The SPL flavonoids and standards were precisely weighed and dissolved in the HPLC grade methanol to prepare the stock solution at the concentration of $1 \mathrm{mg} / \mathrm{ml}$, kept at $4^{\circ} \mathrm{C}$ until use. Standard stock solutions were diluted to $50 \mu \mathrm{g} / \mathrm{mL}$ with methanol and $1 \mathrm{mg}$ / $\mathrm{ml}$ of SPL flavonoids were filtered through $0.22 \mu \mathrm{m}$ membrane and injected into HPLC to detect and compare the retention time and response of each peak with standards. The concentration of standards was adjusted to $25,50,100,150,200 \mu \mathrm{g} / \mathrm{ml}$ for quercetin, myricetrin, tiliroside, quercitrin, isoquercitrin, kaempferol, rhamnetin, CA, 4, 5-CQA, 3, 4, 5-CQA and 100, 200, 300, 400, $500 \mu \mathrm{g} / \mathrm{ml}$ for astragalin according to the response of the SPL flavonoids.

\subsection{Antioxidant activity of SPL flavonoids}

\subsection{1 | Ferric reducing antioxidant power}

FRAP was carried out according to the method of Thaipong, Boonprakob, Crosby, Cisneros-Zevallos, and Byrne (2006) with some modification, the specific procedure was as follows: $10 \mathrm{mmol} / \mathrm{L}$ TPTZ (40 mmol/L HCl was the solvent), $20 \mathrm{mmol} / \mathrm{L} \mathrm{FeCl}_{3}(0.3 \mathrm{~mol} / \mathrm{L}$, $\mathrm{pH}$ 3.6 PBS was the solvent). One portion of TPTZ, 1 portion of $\mathrm{FeCl}_{3}$ and 10 portion of PBS were mixed together and incubated in the water bath at $37^{\circ} \mathrm{C}$ away from light, that was how to prepare the FRAP working solution.

The sample solutions with different flavonoid concentration $(5$, $10,20 \mu \mathrm{g} / \mathrm{ml}$ ) were prepared by diluting with distilled water. An aliquot of $0.15-\mathrm{ml}$ flavonoid sample solution was mixed with $2.85 \mathrm{ml}$ of FRAP working solution, incubated for $30 \mathrm{~min}$ from light at room temperature, and measured the absorbance by spectrophotometer at $593 \mathrm{~nm}$ immediately; the blank control was the mixture while flavonoid sample solution was replaced by distilled water. The scavenging rate was calculated according to the equation:

$$
\text { Scavenging rate }(\%)=\frac{A_{0}-A}{A_{0}} \times 100 \%
$$

$A_{0}$ was the absorbance of the mixture using distilled water to substitute the flavonoids sample solution at $593 \mathrm{~nm}$ and $A$ was the absorbance of the mixture with flavonoids sample solution at $593 \mathrm{~nm}$. The $\mathrm{IC}_{50}$ value was calculated by Graph Pad Prism 6.

\subsection{2 | ABTS. $^{+}$scavenging activity}

According to the method of Li, Lin, Gao, Han, and Chen (2012) with some modification: $2.5 \mathrm{ml}$ of ABTS $(7.4 \mathrm{mM})$ was mixed with $2.5 \mathrm{ml}$ of $\mathrm{K}_{2} \mathrm{~S}_{2} \mathrm{O}_{8}(2.6 \mathrm{mM})$, the mixture was kept quite away from light at $4^{\circ} \mathrm{C}$ for $24 \mathrm{hr}$ to produce $\mathrm{ABTS}{ }^{+}$, then diluted with ethanol for about 50 times to make the absorbance reach to $0.70 \pm 0.02$ at $734 \mathrm{~nm}$ which was $A B T S^{++}$working solution.

Two milliliter $\mathrm{ABTS}^{+}$working solution reacted with $1.0 \mathrm{ml}$ of flavonoids sample solution of different flavonoids concentration (5, $10,20 \mu \mathrm{g} / \mathrm{ml}$ ), incubated for $6 \mathrm{~min}$, and detected their absorbance at $734 \mathrm{~nm}$. The scavenging rate was calculated according to the equation:

$$
\text { Scavenging rate }(\%)=\frac{A_{0}-A}{A_{0}} \times 100 \%
$$

where $A_{0}$ is the absorbance of the mixture using ethanol to substitute the flavonoids sample solution at $734 \mathrm{~nm}$ and $A$ is the absorbance of the mixture with flavonoids sample solution at $734 \mathrm{~nm}$. The $\mathrm{IC}_{50}$ value was calculated by Graph Pad Prism 6.

\subsection{Data analysis}

The data of RSM was processed by Design Expert 8.0, other were analyzed by SAS 8.0. Experiments were carried out in triplicate and data were expressed as mean $\pm S D, p<0.05$ was considered as there was no significant difference.

\section{3 | RESULTS AND DISCUSSION}

\section{1 | Basic components of SPL}

The ash, crude protein, crude fat, and crude fiber content of SPL were $10.47 \pm 0.12,28.79 \pm 0.04,3.28 \pm 0.23$, and $18.49 \pm 0.20 \mathrm{~g} / 100 \mathrm{~g}$ DW and the carbohydrate content was $38.97 \pm 0.28 \mathrm{~g} / 100 \mathrm{~g}$ DW. The flavonoids content of SPL was $5.63 \pm 0.21 \mathrm{~g} / 100 \mathrm{~g}$ DW.

\subsection{Analysis of single-factor experiments}

The effects of UMSE variables, including extraction times, solidliquid ratio, ethanol concentration, extraction temperature, and extraction time on the extraction efficiency (\%) of SPL flavonoids were evaluated by single-factor experiments (Supplement 
Figure 1). For the effect of extraction times on the extraction efficiency of SPL flavonoids, there was no significant difference between 2 and 3 times. Considering the solvent-saving and follow-up concentration operation simplifying, extracted 2 times would be better. For the effect of varying solid-liquid ratio on the extraction efficiency of SPL flavonoids, there was a significant increase when solid-liquid ratio increased from 1:10 to 1:40 and then decreased. This might due to the reason that huge solution volume made complete stirring impossible. In addition, the large volume of solution needed to absorb more energy to heat itself up, thus led to inadequate energy diffusion in ultrasonic and microwave field which would slow down the cell wall breaking and flavonoids leaching (Alara, Abdurahman, \& Olalere, 2018). For the effect of ethanol concentration on the extraction efficiency of SPL flavonoids, the maximum extraction efficiency was obtained at the concentration of $70 \%$, following with the flavonoids decreasing when the ethanol concentration kept increasing. Relative high ethanol concentration made the alcohol-soluble substances dissolved into the solvent easily. For the effect of extraction temperature on the extraction efficiency of SPL flavonoids, there was a significant rising when the temperature reached to $55^{\circ} \mathrm{C}$ compared to $45^{\circ} \mathrm{C}$, which increased $23.10 \%$ then slightly decreased $2.51 \%$ when the temperature kept increasing to $65^{\circ} \mathrm{C}$. Relative high temperature could lower the viscosity of solvent and made bioactive components transferring through cell membrane more easily from plant matrix (Chew et al., 2011), but high-temperature environment could accelerate the bioactive compounds degradation (Alara et al., 2018). The extraction efficiency of SPL flavonoids achieved to maximum when the extraction time lasting to $75 \mathrm{~s}$ compared to $50 \mathrm{~s}$ and $100 \mathrm{~s}$, which were $9.09 \%$ and $2.79 \%$ higher, respectively, ultrasonic and microwave power needed time to transfer the energy to the matrix.

\subsection{Statistical analysis and model fitting of RSM}

The advantage of Box-Behnken design was trying minimum times to obtain the optimal model of the experiment. The experimental and predicted values were shown in Table 1. The analysis of variance was summarized in Table 2. $p$ value of the model was below 0.0001 indicated the model was approximate to the reality $(p<0.05) . X_{1}, X_{2}$, $X_{3}, X_{1} X_{2}, X_{1}^{2}, X_{2}^{2}$, and $X_{3}^{2}$ were below 0.05 showed these factors were quite significant to the extraction efficiency of SPL flavonoids.

The lack of fit was insignificant ( $p=0.6854>0.05)$ represented the model was significant compared to the pure error, which might due to the noise, the model could predict the extraction process quite well. The $R^{2}=0.9793$ indicated the model could explain the $97.93 \%$ of real extraction process, there was only $2.07 \%$ of the total variation could not be explained (Wai, Alkarkhi, \& Easa, 2010). Moreover, the adjusted $R^{2}=0.9526$ showed the high significance of the model, after deleting the insignificant parameters, there was still $95.26 \%$ of the data could be explained by this model.

Three-dimensional plots were chosen to represent the predicted model and the interaction between different parameters. The plots show the interaction between two factors while another was kept at medium level. The response surface plots were shown in Figure $1 \mathrm{~A}-\mathrm{C}$.

\subsection{Interaction of variables on extraction efficiency of SPL flavonoids}

The extraction efficiency of SPL flavonoids, which ranged from $66.61 \pm 1.42 \%$ to $91.65 \pm 3.37 \%$ (Table 1 ), depended on the extraction temperature, extraction time, and ethanol concentration and their interaction (Figure $1 \mathrm{~A}-\mathrm{C}$ ). Extraction temperature was the

TAB LE 2 Analysis of variance (ANOVA) for response surface model

\begin{tabular}{|c|c|c|c|c|c|c|}
\hline Source & Sum of squares & $d f$ & Mean square & F Value & $p$-value Prob $>F$ & \\
\hline Model & 1.82 & 9 & 0.2 & 36.73 & $<0.0001$ & Significant \\
\hline A-temperature & 0.87 & 1 & 0.87 & 158.51 & $<0.0001$ & \\
\hline B-time & 0.22 & 1 & 0.22 & 39.32 & 0.0004 & \\
\hline C-concentration & 0.061 & 1 & 0.061 & 10.98 & 0.0129 & \\
\hline$A B$ & 0.12 & 1 & 0.12 & 22.23 & 0.0022 & \\
\hline$A C$ & 4.00E-04 & 1 & 4.00E-04 & 0.073 & 0.7954 & \\
\hline$B C$ & 0.018 & 1 & 0.018 & 3.31 & 0.1118 & \\
\hline$A^{\wedge}$ & 0.83 & 1 & 0.83 & 150.45 & $<0.0001$ & \\
\hline $\mathrm{B}^{\wedge}$ & 0.22 & 1 & 0.22 & 39.11 & 0.0004 & \\
\hline$C^{\wedge 2}$ & 0.12 & 1 & 0.12 & 22.41 & 0.0021 & \\
\hline Residual & 0.039 & 7 & $5.51 \mathrm{E}-03$ & & & \\
\hline Lack of fit & 0.011 & 3 & $3.66 \mathrm{E}-03$ & 0.53 & 0.6854 & Not significant \\
\hline Pure error & 0.028 & 4 & 6.90E-03 & & & \\
\hline Cor total & 1.86 & 16 & & & & \\
\hline$R^{2}$ & & & 0.9793 & & & \\
\hline $\operatorname{Adj} R^{2}$ & & & 0.9526 & & & \\
\hline Pred $R^{2}$ & & & 0.8824 & & & \\
\hline
\end{tabular}


(A)

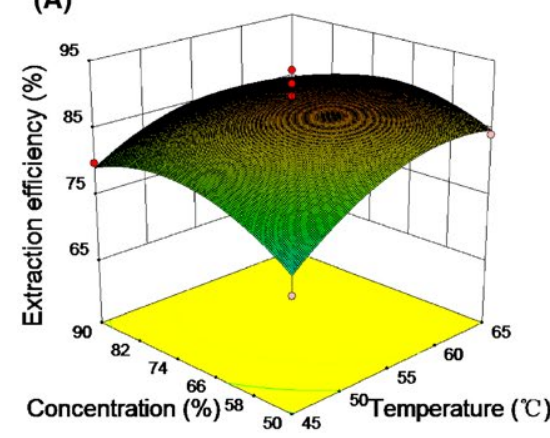

(B)

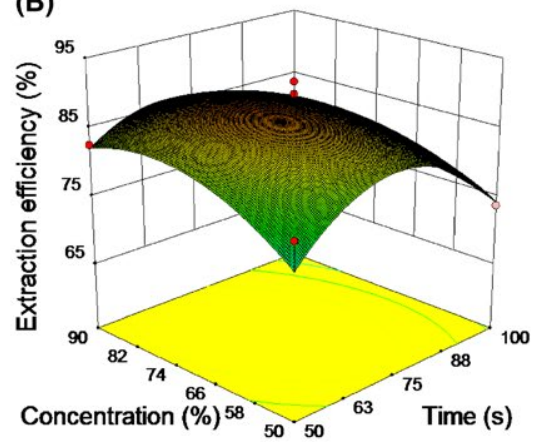

(C)

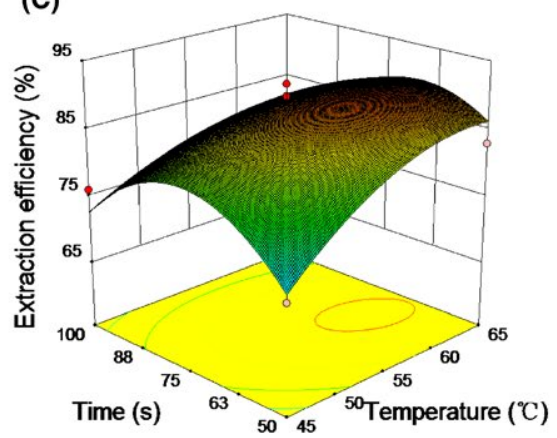

FIGURE 1 Three-dimensional diagrams of extraction temperature, extraction time, and ethanol concentration on the extraction efficiency of SPL flavonoids (A: Interaction of extraction temperature and ethanol concentration on the extraction efficiency of SPL flavonoids; B: Interaction of extraction time and ethanol concentration on the extraction efficiency of SPL flavonoids; C: Interaction of extraction temperature and extraction time on the extraction efficiency of SPL flavonoids)

most important factor ( $p$-value $<0.0001)$ for the extraction which affected the extraction efficiency of SPL flavonoids effectively. The result showed that for the extraction temperature rising from 45 to $65^{\circ} \mathrm{C}$, the extraction efficiency of SPL flavonoids was shown first rising then falling tendency. The increase of extraction temperature could definitely enhance the flavonoids dissolving, but high temperature would also affect the stability of flavonoids and induced them degradating rapidly.

Extraction time was the second critical factor for the extraction. We could see from Figure 1B,C that increased time from 50 to $100 \mathrm{~s}$ could enhance the microwave and ultrasonic reacted with the sample and accelerated the solvent and energy penetrating into the matrix, but too much time of severe reaction would definitely destroy the chemical bonds of flavonoids and induced them dissociating (Wong et al., 2017).

Ethanol concentration was also vital for the extraction because it decided the polarity of the whole system. When the ethanol concentration changed from $50 \%$ to $90 \%$, the extraction efficiency showed first rising then falling tendency as we saw from Figure 1A,B. Flavonoids were a class of weak polarity organic compounds which could dissolved in high percentage of ethanol easily. If the ethanol concentration was not high enough there were a large number of water-soluble impurities escaped into the solution, and if the ethanol concentration was too high that meant the polarity of the solution was not high enough to dissolve the flavonoids completely.

\section{5 | Optimization of extraction condition and method validation}

According to the results and discussion, the optimum extraction was required to find the desire condition for maximizing the extraction efficiency of SPL flavonoids, the extraction temperature was $57^{\circ} \mathrm{C}$, the extraction time was $76 \mathrm{~s}$, the ethanol concentration was $72 \%$, solidliquid ratio was 1:40, and extracted 2 times according to the above condition, the maximum extraction efficiency of SPL flavonoids was $91.65 \pm 3.37 \%$, the predicted maximum extraction efficiency fitted by the software was $89.17 \%$ which correlated quite well with the actual data, demonstrated the model could simulate the reality and the optimum condition was quite valid for this experiment.

\section{6 | Purification of SPL flavonoids}

The crude solution extracted by optimum parameters then went through liquid-liquid extraction to get petroleum ether phase, ethyl acetate phase, and water phase. The purity of SPL flavonoids in ethanol extract was $16.81 \pm 0.76$ (\%, DW) and in ethyl acetate phase it was rising up to $76.10 \pm 3.11(\%, \mathrm{DW})$.

\section{7 | Qualitative and quantitative analysis of SPL flavonoids}

Qualitative and quantitative analyses were shown in Figure 2, Supplement Figure 2 and Table 3. There were 11 flavonoids detected in SPL flavonoids which were CA, 4,5-CQA, myricetrin, 3,4,5-CQA, isoquercitrin, astragalin, quercitrin, tiliroside, quercetin, kaempferol, and rhamnetin according to the references and comparing to the retention time of standards (Anastácio \& Carvalho, 2013; Ojong et al., 2008; Xi et al., 2015). Astragalin was the highest amount of flavonoids in SPL flavonoids, which was $473.8 \pm 7.3 \mathrm{mg} / \mathrm{g} \mathrm{DW}$, followed by quercitrin ( $86.5 \pm 0.7 \mathrm{mg} / \mathrm{g} \mathrm{DW}), 4,5-\mathrm{CQA}(76.4 \pm 0.5 \mathrm{mg} / \mathrm{g} \mathrm{DW})$, isoquercitrin $(62.4 \pm 0.4 \mathrm{mg} / \mathrm{g} \mathrm{DW})$, tiliroside $(18.8 \pm 0.3 \mathrm{mg} / \mathrm{g} \mathrm{DW})$, quercetin (12.5 $\pm 0.2 \mathrm{mg} / \mathrm{g} \mathrm{DW}), 3,4,5-\mathrm{CQA}(6.5 \pm 0.2 \mathrm{mg} / \mathrm{g} \mathrm{DW})$, CA (6.1 $\pm 0.2 \mathrm{mg} / \mathrm{g} \mathrm{DW})$, kaempferol $(6.0 \pm 0.2 \mathrm{mg} / \mathrm{g})$, myricetrin $(5.9 \pm 0.1 \mathrm{mg} / \mathrm{g} D W)$, and rhamnetin $(4.3 \pm 0.1 \mathrm{mg} / \mathrm{g} D W)$. Ojong et al. (2008) found out that apigenin, kaempferol, luteolin, quercetin, and myricetin existed in SPL usually grown in Southern United States. Anastácio and Carvalho (2013) also took the research on purple SPL flavonoids and luteolin, myricetin, and quercetin were detected. There were some differences between our results which might due to the different cultivar contained different flavonoid monomer, the difference of physiological stage of the plant or cultural practices. 


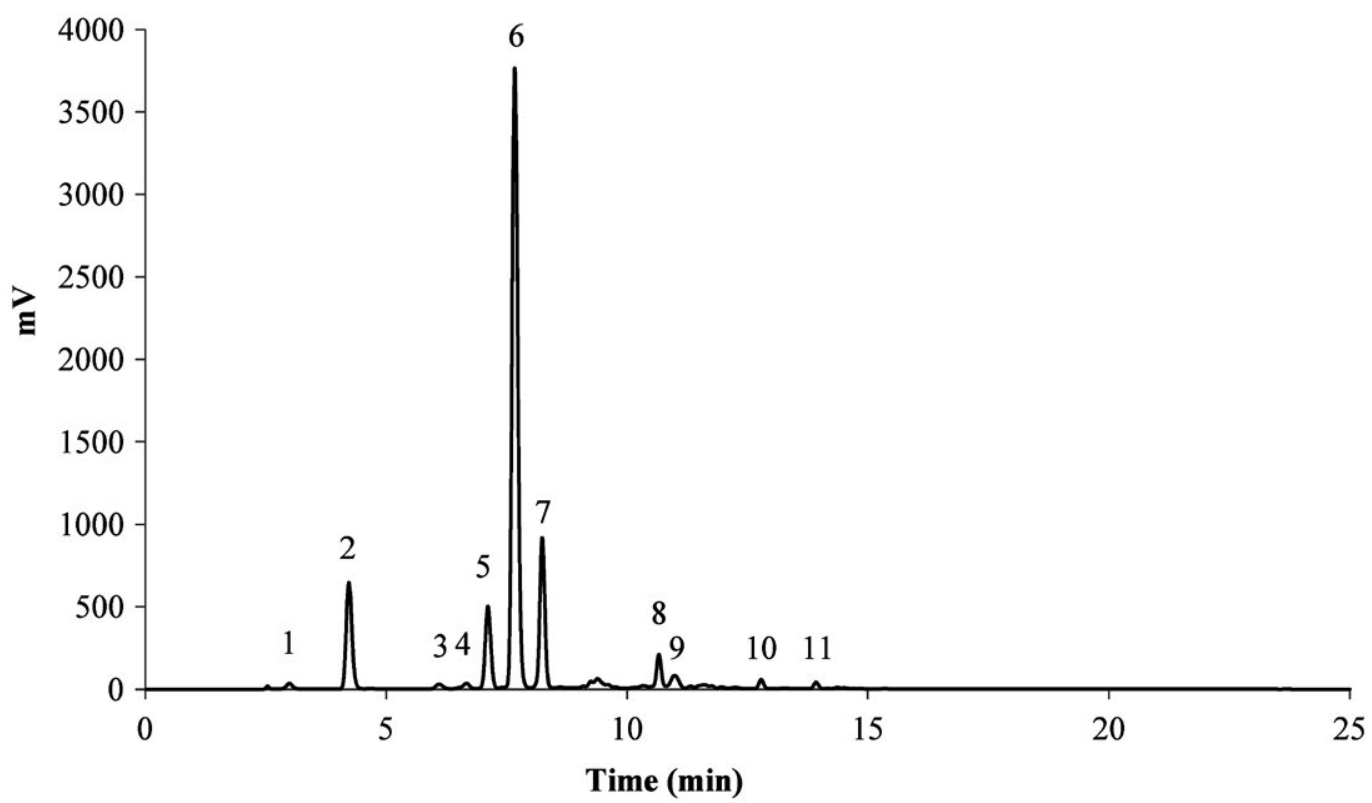

FIG URE 2 The HPLC chromatography of SPL flavonoids. Peak 1: CA, peak 2:4, 5-CQA, peak 3: myricetrin, peak 4:3, 4, 5-CQA, peak 5: isoquercitrin, peak 6: astragalin, peak 7: quercitrin, peak 8: tiliroside, peak 9: quercetin; peak 10: kaempferol, peak 11: rhamnetin

TAB LE 3 Qualitative and quantitative analysis of SPL flavonoids by HPLC

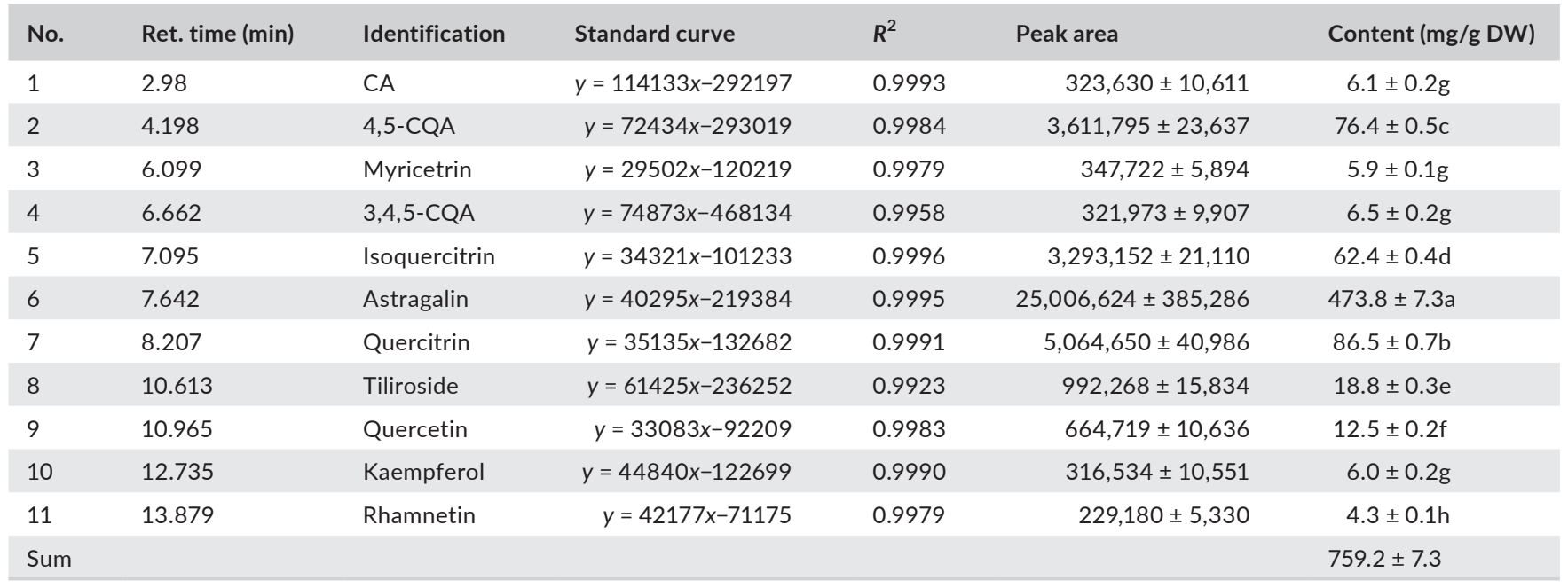

Note. Different letters $(\mathrm{a}-\mathrm{h})$ mean values are significantly different $(p<0.05)$.

\subsection{Antioxidant activity of SPL flavonoids}

Antioxidant activity of SPL flavonoids were evaluated by FRAP and ABTS method. The results were shown in Figure $3 A, B$. The flavonoids purity of SPL flavonoids, soy isoflavones, ginkgo biloba extract, and propolis flavone were $76.10 \pm 3.11 \mathrm{a}, 59.32 \pm 3.20 \mathrm{~b}, 45.77 \pm 3.34 \mathrm{c}$, and $56.85 \pm 2.78 \mathrm{~b}(\%, \mathrm{DW})$, respectively.

Figure $3 \mathrm{~A}$ showed the $\mathrm{Fe}^{3+}$ scavenging capacities of SPL flavonoids and soy isoflavones, ginkgo biloba extract, and propolis flavone at the concentration of 5,10 , and $20 \mu \mathrm{g} / \mathrm{ml}$, SPL flavonoids had the significant advantage than the other three positive controls. The $\mathrm{Fe}^{3+}$ scavenging capacities of SPL flavonoids was $17.74 \pm 1.95 \%$, $37.36 \pm 0.98$, and $76.22 \pm 0.49 \%$ at the concentration of 5,10 , and $20 \mu \mathrm{g} / \mathrm{ml}$, which was approximately 0.31 times and 3.08 times higher than ginkgo biloba extract and propolis flavone at the concentration of $5 \mu \mathrm{g} /$ $\mathrm{ml}, 0.18$ times and 2.25 times higher than ginkgo biloba extract and propolis flavone at the concentration of $10 \mu \mathrm{g} / \mathrm{ml}$ and 0.23 times and 1.80 times higher than ginkgo biloba extract and propolis flavone at the concentration of $20 \mu \mathrm{g} / \mathrm{ml}$. Soy isoflavones showed poor activity in this experiment. $\mathrm{IC}_{50}$ values of SPL flavonoids, soy isoflavones, ginkgo biloba extract, and propolis flavone were 13.26 \pm 0.09 a, $143.71 \pm 1.33 \mathrm{~d}, 15.99 \pm 0.11 \mathrm{~b}$, and $34.01 \pm 0.68 \mathrm{c} \mu \mathrm{g} / \mathrm{ml}$, respectively.

Figure $3 \mathrm{~B}$ showed $\mathrm{ABTS}{ }^{+}$scavenging capacity at the flavonoids concentration of 5,10 , and $20 \mu \mathrm{g} / \mathrm{ml}$. The $\mathrm{ABTS}^{+}$scavenging rate of 
(A)

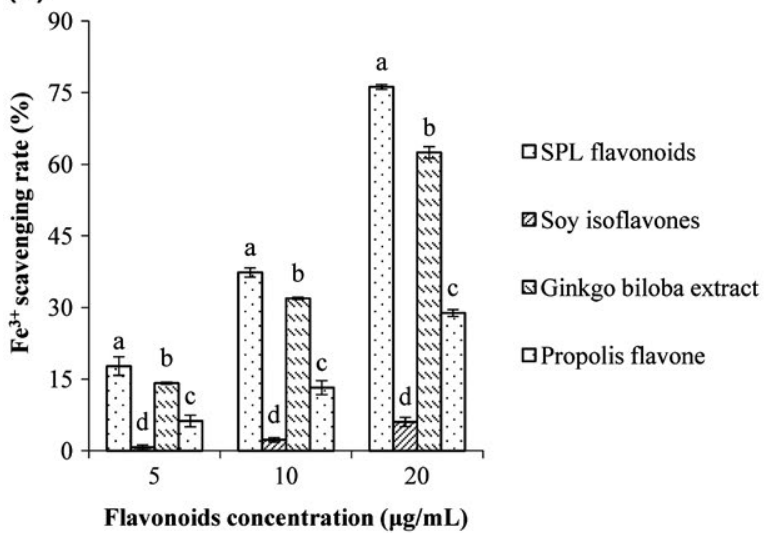

(B)

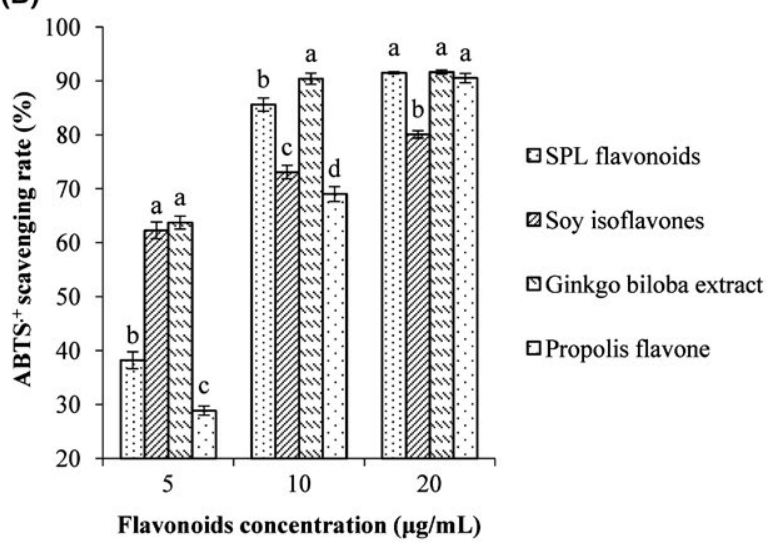

FIG URE 3 Antioxidant activities of SPL flavonoids. (A) Fe ${ }^{3+}$ scavenging capacity. (B) ABTS.+ scavenging capacity Note. Different letters (a-d) mean values are significantly different $(p<0.05)$.

SPL flavonoids at the concentration of $5 \mu \mathrm{g} / \mathrm{ml}$ was $38.21 \pm 1.56 \%$, which was $61.34 \%, 59.93 \%$, and $132.35 \%$ of scavenging capacity comparing to the corresponding concentration of soy isoflavones, ginkgo biloba extract, and propolis flavone. When the concentration reached to $10 \mu \mathrm{g} / \mathrm{ml}$, the $\mathrm{ABTS}^{+}$scavenging rate of SPL flavonoids achieved to $85.63 \pm 1.22 \%$, which was $17.14 \%$ and $24.03 \%$ higher than soy isoflavones and propolis flavone and $5.30 \%$ a little lower than ginkgo biloba extract. When the concentration reached up to $20 \mu \mathrm{g} / \mathrm{mL}$, the $\mathrm{ABTS}^{+}$scavenging rate of SPL flavonoids achieved to $91.52 \pm 0.17 \%$, which was $14.26 \%$ higher than soy isoflavones and had no significant difference between ginkgo biloba extract and propolis flavone. $\mathrm{IC}_{50}$ values of SPL flavonoids, soy isoflavones, ginkgo biloba extract, and propolis flavone were $5.41 \pm 0.21 \mathrm{c}$, $2.11 \pm 0.06 \mathrm{a}, 3.20 \pm 0.09 \mathrm{~b}$, and $6.99 \pm 0.11 \mathrm{~d} \mu \mathrm{g} / \mathrm{ml}$, respectively.

The antioxidant activity is related to many factors, including the structure of the flavonoids from different sources, other ingredients in the flavonoid sample (Chen et al., 2017). In addition, it has been reported that daidzin and genistin were the dominant flavonoids in soy isoflavones (Szymczak et al., 2017), quercetin, kaempferol, and isorhamnetin were the dominant flavonoids in ginkgo biloba extract (Sati, Dhyani, Bhatt, \& Pandey, 2017), rutin, isorhamnetin, kaempferol, luteolin, naringenin, and quercetin-3-glucoside were the main flavonoids detected in propolis flavone (Andrade et al., 2018), which meant the difference of antioxidant activity among SPL flavonoids, soy isoflavones, ginkgo biloba extract, and propolis flavone might also due to the differences of flavonoids composition.

\section{4 | CONCLUSION}

The results showed that the highest extraction efficiency of SPL flavonoids at the optimum condition (extraction temperature was $57^{\circ} \mathrm{C}$, extraction time was $76 \mathrm{~s}$, ethanol concentration was $72 \%$, solid-liquid ratio ( $\mathrm{w} / \mathrm{v}$ ) was $1: 40$, and extracted 2 times) was $91.65 \pm 3.37 \%$, which was confirmed through the validation experiment $89.17 \%$. The crude extract was selected by petroleum ether and ethyl acetate, the latter phase was collected to obtain the SPL flavonoids with the purity of $76.10 \pm 3.11$ (\%, DW). HPLC analysis results showed that the SPL flavonoids mainly consisted of astragalin, quercetrin, 4, 5-CQA, isoquercitrin, tiliroside, quercetin, 3, 4, 5-CQA, CA, kaempferol, myricetrin, and rhamnetin, which possessed high antioxidant capacity. Meanwhile, UMSE was an economic method to obtain SPL flavonoids which was time-saving and easy to scale up at the pilot test and industrial scale, providing a potential possibility for industrial extraction of flavonoids from SPL, enriching the flavonoids health products market.

\section{ACKNOWLEDGMENTS}

The authors gratefully acknowledge the Natural Science Funding of China (31701614), the National Key R\&D Program of China (2016YFE0133600), the earmarked fund for China Agriculture Research System (CARS-10-B21), and the Collaborative Innovation Task of CAAS (CAAS-XTCX2016005). The authors are grateful to Chongqing Sweet Potato Engineering and Technology Research Center (Chongqing, China) for providing the sweet potato leaves in this study.

\section{CONFLICT OF INTEREST}

The authors have declared no conflicts of interest for this article.

\section{ORCID}

Taihua Mu iD https://orcid.org/0000-0002-1308-0121

\section{REFERENCES}

Alara, O. R., Abdurahman, N. H., \& Olalere, O. A. (2018). Optimization of microwave-assisted extraction of flavonoids and antioxidants from 
Vernonia amygdalina leaf using response surface methodology. Food and Bioproducts Processing, 107, 36-48. https://doi.org/10.1016/ j.fbp.2017.10.007

Anastácio, A., \& Carvalho, I. S. (2013). Spotlight on PGI sweet potato from Europe: Study of plant part, time and solvent effects on antioxidant activity. Journal of Food Biochemistry, 37(5), 628-637. https:// doi.org/10.1111/jfbc.12017

Andrade, J. K. S., Denadai, M., Andrade, G. R. S., Nascimento, C. D. C., Barbosa, P. F., Jesus, M. S., \& Narain, D. (2018). Development and characterization of microencapsules containing spray dried powder obtained from Brazilian brown, green and red propolis. Food Research International, 109, 278-287. https://doi.org/10.1016/ j.foodres.2018.04.048

Chemat, F., Zill-e-Huma, \& Khan, M. K. (2011). Applications of ultrasound in food technology: Processing, preservation and extraction. Ultrasonics Sonochemistry, 18(4), 813-835. https://doi.org/10.1016/ j.ultsonch.2010.11.023

Chen, C. M., Li, S. C., Chen, C. Y., Au, H. K., Shih, C. K., Hsu, C. Y., \& Liu, J. F. (2011). Constituents in purple sweet potato leaves inhibit in vitro angiogenesis with opposite effects ex vivo. Nutrition, 27(11), 1177-1182. https://doi.org/10.1016/j.nut.2011.01.005

Chen, Y., Fu, Z. F., Tu, Z. C., Wang, H., Zhang, L., Xie, X., \& Liu, G. (2017). Influence of in vitro gastrointestinal digestion on the bioavailability and antioxidant activity of polyphenols from Ipomoea batatas leaves. International Journal of Food Science and Technology, 52(5), 1131-1137. https://doi.org/10.1111/ijfs.13377

Chew, K. K., Ng, S. Y., Thoo, Y. Y., Khoo, M. Z., Aida, W. M. W., \& Ho, C. W. (2011). Effect of ethanol concentration, extraction time and extraction temperature on the recovery of phenolic compounds and antioxidant capacity of Orthosiphon stamineus extracts. International Food Research Journal, 8(1), 1-9. https://doi.org/10.1016/ j.jep.2007.07.023

Dahmoune, F., Spigno, G., Moussi, K., Remini, H., Cherbal, A., \& Madani, K. (2014). Pistacia lentiscus leaves as a source of phenolic compounds: Microwave-assisted extraction optimized and compared with ultrasound-assisted and conventional solvent extraction. Industrial Crops and Products, 61, 31-40. https://doi.org/10.1016/ j.indcrop.2014.06.035

Derrien, M., Badr, A., Gosselin, A., Desjardins, Y., \& Angers, P. (2017). Optimization of a green process for the extraction of lutein and chlorophyll from spinach by-products using response surface methodology (RSM). LWT-Food Science and Technology, 79, 170-177. https:// doi.org/10.1016/j.Iwt.2017.01.010

Ferreira, S. L. C., Bruns, R. E., Ferreira, H. S., Matos, G. D., David, J. M., Brandão, G. C., ... dos Santos, W. N. L. (2007). Box-Behnken design: An alternative for the optimization of analytical methods. Analytica Chimica Acta, 597(2), 179-186. https://doi.org/10.1016/ j.aca.2007.07.011

Fu, Z. F., Tu, Z. C., Zhang, L., Wang, H., Wen, Q. H., \& Huang, T. (2016). Antioxidant activities and polyphenols of sweet potato (Ipomoea batatas L.) leaves extracted with solvents of various polarities. Food Bioscience, 15, 11-18. https://doi.org/10.1016/j.fbio.2016. 04.004

Huang, X., Tu, Z., Xiao, H., Li, Z., Zhang, Q., Wang, H., ... Zhang, L. (2013). Dynamic high pressure microfluidization-assisted extraction and antioxidant activities of sweet potato (Ipomoea batatas L.) leaves flavonoid. Food and Bioproducts Processing, 91(1), 1-6. https://doi. org/10.1016/j.fbp.2012.07.006

Isabelle, M., Lee, B. L., Lim, M. T., Koh, W. P., Huang, D., \& Ong, C. N. (2010). Antioxidant activity and profiles of common vegetables in Singapore. Food Chemistry, 120(4), 993-1003. https://doi. org/10.1016/j.foodchem.2009.11.038

Li, X., Lin, J., Gao, Y., Han, W., \& Chen, D. (2012). Antioxidant activity and mechanism of Rhizoma Cimicifugae. Chemistry Central Journal, 6(1), 140. https://doi.org/10.1186/1752-153X-6-140
Liao, W. C., Lai, Y. C., Yuan, M. C., Hsu, Y. L., \& Chan, C. F. (2011). Antioxidative activity of water extract of sweet potato leaves in Taiwan. Food Chemistry, 127(3), 1224-1228. https://doi. org/10.1016/j.foodchem.2011.01.131

Lu, B., Wang, Z., Xie, X., \& Ding, L. (2013). Study on extracting chlorogenic acid and flavonoids from Eucommia leaves. Journal of Anhui Agricultural Sciences, 19, 052.

Mandal, V., Mohan, Y., \& Hemalatha, S. (2007). Microwave assisted extraction-an innovative and promising extraction tool for medicinal plant research. Pharmacognosy Reviews, 1(1), 7-18.

Miu, N., Mariko, T., Yoshimi, K., Maki, I., Emi, S., Miku, T., ... Kondo, K. (2011). Sweet potato (Ipomoea batatas L.) leaves suppressed oxidation of low density lipoprotein (LDL) in vitro and in human subjects. Journal of Clinical Biochemistry \& Nutrition, 48(3), 203-208. https:// doi.org/10.3164/jcbn.10

Mustapa, A. N., Martin, A., Gallego, J. R., Mato, R. B., \& Cocero, M. J. (2015). Microwave-assisted extraction of polyphenols from Clinacanthus nutans Lindau medicinal plant: Energy perspective and kinetics modeling. Chemical Engineering and Processing: Process Intensification, 97, 66-74. https://doi.org/10.1016/j.cep.2015. 08.013

Ojong, P. B., Njiti, V., Guo, Z., Gao, M., Besong, S., \& Barnes, S. L. (2008). Variation of flavonoid content among sweetpotato accessions. Journal of the American Society for Horticultural Science American Society for Horticultural Science, 133(6), 819-824. https://doi. org/10.21273/JASHS.133.6.819

Petkova, N., Ivanov, I., Vrancheva, R., Denev, P., \& Pavlov, A. (2016). Ultrasound and microwave-assisted extraction of elecampane (Inula helenium) roots. Natural Product Communications, 12(2), 171-174. http://amapseec.com/NPC-12-2-2017.pdf

Saleh, I. A., Vinatoru, M., Mason, T. J., Abdel-Azim, N. S., Aboutabl, E. A., \& Hammouda, F. M. (2016). A possible general mechanism for ultrasound-assisted extraction (UAE) suggested from the results of UAE of chlorogenic acid from Cynara scolymus L. (artichoke) leaves. Ultrasonics Sonochemistry, 31, 330-336. https://doi.org/10.1016/ j.ultsonch.2016.01.002

Sati, P., Dhyani, P., Bhatt, I. D., \& Pandey, A. (2017). Ginkgo biloba flavonoid glycosides in antimicrobial perspective with reference to extraction method. Journal of Traditional and Complementary Medicine, 9(1), 15-23. https://doi.org/10.1016/j.jtcme.2017.10.003

Shi, G. Q., Yang, J., Liu, J., Liu, S. N., Song, H. X., Zhao, W. E., \& Liu, Y. Q. (2016). Isolation of flavonoids from onion skins and their effects on K562 cell viability. Bangladesh Journal of Pharmacology, 11(S1), 18-25. https://doi.org/10.3329/bjp.v11iS1.26419

Sun, H., Mu, T., Xi, L., Zhang, M., \& Chen, J. (2014). Sweet potato (Ipomoea batatas L.) leaves as nutritional and functional foods. Food Chemistry, 156, 380-389. https://doi.org/10.1016/j.foodchem. 2014.01.079

Szymczak, G., Wójciak-Kosior, M., Sowa, I., Zapała, K., Strzemski, M., \& Kocjan, R. (2017). Evaluation of isoflavone content and antioxidant activity of selected soy taxa. Journal of Food Composition and Analysis, 57, 40-48. https://doi.org/10.1016/j.jfca.2016.12.015

Taira, J., Taira, K., Ohmine, W., \& Nagata, J. (2013). Mineral determination and anti-LDL oxidation activity of sweet potato (Ipomoea batatas L.) leaves. Journal of Food Composition \& Analysis, 29(2), 117-125. https://doi.org/10.1016/j.jfca.2012.10.007

Thaipong, K., Boonprakob, U., Crosby, K., Cisneros-Zevallos, L., \& Byrne, D. H. (2006). Comparison of ABTS, DPPH, FRAP, and ORAC assays for estimating antioxidant activity from guava fruit extracts. Journal of Food Composition \& Analysis, 19(6), 669-675. https://doi. org/10.1016/j.jfca.2006.01.003

Wai, W. W., Alkarkhi, A. F. M., \& Easa, A. M. (2010). Effect of extraction conditions on yield and degree of esterification of durian rind pectin: An experimental design. Food and Bioproducts Processing, 88(2), 209-214. https://doi.org/10.1016/j.fbp.2010.01.010 
Wong, K. H., Li, G. Q., Li, K. M., Razmovski-Naumovski, V., \& Chan, K. (2017). Optimisation of Pueraria isoflavonoids by response surface methodology using ultrasonic-assisted extraction. Food Chemistry, 231, 231-237. https://doi.org/10.1016/j.foodchem.2017.03.068

Xi, L., Mu, T., \& Sun, H. (2015). Preparative purification of polyphenols from sweet potato (Ipomoea batatas L.) leaves by AB-8 macroporous resins. Food Chemistry, 172, 166-174. https://doi.org/10.1016/ j.foodchem.2014.09.039

Zhang, J. L., Luo, C. L., Zhou, Q., \& Zhang, Z. C. (2018). Isolation and identification of two major acylated anthocyanins from purple sweet potato (Ipomoea batatas L. cultivar Eshu No. 8) by UPLC-QTOF-MS/ MS and NMR. International Journal of Food Science and Technology, 53(8), 1932-1941. https://doi.org/10.1111/ijfs.13780

\section{SUPPORTING INFORMATION}

Additional supporting information may be found online in the Supporting Information section at the end of the article.

How to cite this article: Liu J, Mu T, Sun H, Fauconnier ML. Optimization of ultrasonic-microwave synergistic extraction of flavonoids from sweet potato leaves by response surface methodology. J Food Process Preserv. 2019;43:e13928.

https://doi.org/10.1111/jfpp.13928 